\title{
Work-Life Balance, Upward Career Mobility and Further Education: The Case for Working Mothers
}

\author{
Marisabelle Camilleri \\ Pegaso International and MCAST, Malta \\ marisabelle.camilleri@mcast.edu.mt \\ Damian Spiteri \\ University of Malta, Malta \\ damian.spiteri@um.edu.mt
}

Purpose: This paper aims to explore how working mothers make sense and respond to their professional desires, responsibilities and expectations within the context of motherhood. It also seeks to explore what it takes for mothers to live up to their potential at work, what it takes for mothers to reach top positions in their field of work and the challenges they face. All of this with the ultimate aim of pooling opinions as to which incentives, strategies or measures can help reduce the conflict between family life and work.

Study design/methodology/approach: Via a phenomenological approach and through the lens of social constructivism, this qualitative study is based on interviews with seven mothers holding executive or managerial positions in Malta.

Findings: Balancing family and work proves to be extremely difficult, especially when the mother holds executive or managerial roles, and this comes with much stress and requires constant planning and organisation, time management, perseverance, resilience, spousal and parental support, and completely sacrificing one's time for hobbies or similar interests. Mothers' innate drive to prioritise their families caused all of the interviewees to shape their careers or studies around family responsibilities, with all but one opting for career breaks when their children were still young, yet such a decision was never regretted. All the interviewees chose to pursue self-actualising roles at work at some point or another. Such an intrinsic drive to reach their full potential caused almost all of the interviewees to further their studies up to a certain extent.

Originality/value: This paper provides raw insights into the struggles working mothers face when balancing work and family life, primarily if the mother seeks to actualise herself via a fulfilling career. The paper presents recommendations for policymakers, employers and society as a whole on how mothers' potential in the workforce can be cultivated.

\section{Introduction}

Various studies (Aveling, 2002; Baber and Monaghan, 1988; Bielby and Bielby, 1984; Bhattacharyya, 2009; 2016; Granrose and Caplan, 1996; Herman and Lewis, 2012; Hoffnung, 2004, 2011; Lahiri-Dutt and Sil, 2014) claim that it is tough for women to "have it all" in terms of financial stability, marriage, children, and career. This refers not only to those working in STEM (science, technology, engineering, mathematics) sectors (Herman and Lewis, 2012) but also in other areas of economic activity too (Bhattacharyya, 2016). In a 2021 report by McKinsey and Co., it is stated that "women continue to face a "broken rung" at the first step up to manager: for every 100 men promoted to manager, only 86 women are promoted. As a result, men significantly outnumber women at the managerial level, which means there are far fewer women to promote to higher levels. The broken rung likely explains why the representation of women at the senior manager, director, and VP levels has improved more slowly than the pipeline overall".

Other more dated studies also convey that it is challenging for mothers in different fields of work to progress to top positions (Belkin, 2003; Zemon and Harrison Bahr, 2005; Ranson, 
2005). Some women may delay becoming mothers altogether (Miller, 2008) or become selfemployed (Duberley and Carrigan, 2012) as an alternative. Herman and Lewis (2012) and McIntosh et al. (2012) also portray how benefitting from family-friendly measures at work often forfeits chances for career progression in various sectors, whilst Brown (2010) shows that great conflict between home life and work still ensues irrespective of any adopted family-friendly measures. Going back in time, women did not have many labour market opportunities. Upon reaching motherhood, most women used to leave the labour market due to family responsibilities or opt for part-time employment. The present government's goal is to raise the female employment rate, as can be seen by the opening of new childcare facility services and reducing national insurance and taxes to women bearing children. Historically, gender discrimination in the working environment was common practice in Malta; and it was commonplace for male candidates to be preferred since females were destined to take a long time off work due to pregnancy and related childcare matters. Right up to the early decades in the post-war era, members of the teaching profession, who were females, were forced to choose between either getting married or working; they could not do both.

In 2018, in Malta, $57.1 \%$ of mothers with children up to 17 years participated in gainful employment 2016 , with $61.8 \%$ of them engaged in full-time employment. The rate of employed fathers, on the other hand, amounted to $95.6 \%$ in 2016 (NSO, 2018). Add to this discrepancy, female underrepresentation in senior positions in Malta ensues, with only $7 \%$ female managers compared to 11\% male ones in 2015 in Malta (NSO, 2015). Hence, this research aims to shed light on the challenges mothers face in participating in the world of work and possibly, developing their careers further and advancing in their careers.

According to a study by KMPG (2015) issued by the Centre for Labour Studies at the University of Malta, $50 \%$ of female managers in Malta are childless. Furthermore, the statement "women generally have less freedom to pursue their career due to family/children responsibilities" was the most significant for male and female respondents. The issue of "work-life balance" and "coping with responsibilities outside work" was cited as the main culprit for the female underrepresentation in managerial positions in Malta. "Getting the work-life balance right" was also cited as the main challenge of occupying CEO positions (Pace, 2017).

In light of this, this paper aims to explore how mothers make sense and respond to their professional desires, responsibilities and expectations within the context of motherhood by, first and foremost, delving deeper into the compromises, if any, these mothers are constrained to do, in order to strike a balance between work and family life. Another aim of this paper is to explore if working mothers forfeit developing their careers further for motherhood responsibilities. What does it take for mothers to live up to their potential at work? Is there any lost potential in this regard? Are there any ways by which such a situation can be mitigated? Thirdly, this paper shall also identify what it takes for mothers to reach top positions in their field of work, the challenges they face and how easy or difficult it is to attain and maintain such positions. The ultimate aim is to pool opinions on which incentives, strategies or measures can help reduce any conflict between family life and work. With this in mind, employers would have a clearer insight into how to feasibly help harmonise the balance between the two and adopt ways that foster self-growth and facilitate mothers' self-actualisation at work. This generates greater fulfilment at work for the working mother, in turn maximising her value and input in the organisation.

\section{Literature review}

A central tenet of this paper is that motherhood is socially and culturally constructed. Up to a few years ago - perhaps even to this day - in several societies, including Malta, intensive mothering with its whole emotionally demanding and time-consuming child-centricity (Hays, 
1996), has been presented as the predominant women's discourse (Hays, 1996; Hilbrecht et al., 2008). This discourse often leads to setting standards that mothers feel obliged to reach to be seen as performing optimally in society. The child-caring role is seen as central to mothering, and it is given a dominant position in a woman's life.

From a social constructionist perspective, the assigning of this dominant position to mothering comes about since the discourses and constructions of motherhood that are embedded in society are internalised by individual women, that utilise them as standards against which they tally their own experiences and practices to form their own ideologies (Elvin-Nowak and Thomsson 2001).

This prevailing discourse of being a mother over being a worker can only be understood concerning other prevailing discourses about what it means to be a good mother. Ferdinand de Saussure, the father of structuralism, explained this when he stated that the meaning of a text is influenced by the way a language is structured. A sign can only convey meaning if it is differentiated from other signs in the system of signs. Likewise, from a social constructionist viewpoint, what it means to be a good mother cannot be objectified, as there is never a 'signified.' The notion of being a good mother is constructed by discourse participants in their various discourse communities as a collective. For this reason, there is no one way to be a good mother and combine this with being a working mother. Instead, there are likely many ways in which society can see them as 'good' mothers to their children and combine work with this discourse.

However, there are competing dominant discourses, such as a prevailing belief that "a woman's place is in the home". In that case, working mothers would likely divest themselves of their own self-identity to be 'good' mothers to their children (Hays, 1996). For instance, 'working mother guilt' may hinder a mother from engaging in work. This may arise, for instance, when responsibilities are not equally shared between working mothers and their partners (Bailey, 2000; Borg, 2011). Working mother guilt may also be augmented by what has been described as a "historical bias against motherhood" in the sense that in universities, working mothers are believed to drop out more and to progress academically at a slower rate and thereby perform less well than male or childless female counterparts (Brus, 2006; Kmec, 2013; Mason and Goulden, 2004; Mason et al., 2013). This is likely to follow the belief that since mothers tend to assume most caregiving roles, academic mothers experience greater "stress and pressure" than fathers, especially in managing the dual roles of being a parent and an academic (Wilton and Ross, 2017). This belief that working mothers are less likely to perform optimally in academic tasks is summed up by Young and Wright (2001, p.560) when stating that (for working mothers) "the balance of family and work (is likely to be) ... exhausting and overwhelming under the best of circumstances". When considering Maltese couples with children, only $49 \%$ of women compared to $91 \%$ of men are employed full-time. This gap is higher when compared to the percentages of couples without children. Couples with children report having $96 \%$ of women regularly carry out cooking and housework, whereas only $31 \%$ of men carry out these tasks on the same frequency (European Institute for Gender Equality, 2018).

Spousal positive reinforcement and support are crucial for mothers to maintain a career (Whitmarsh, 2007; Wingfield, 2011). Shared family and household responsibilities are also important (Borg, 2011) and may be influenced by language. From a social constructionist perspective, language does not only describe reality but co-constitutes it. Why is it acceptable to speak about a working mother, but had we to speak about a working father, this would be likely to raise eyebrows, at least in certain cultures? Nightingale and Cromby (2002) explain that there is "a play of linguistic meaning and signification in force that is shaped and 
constrained by embodiment, materiality, socio-cultural institutions, interpersonal practices and their historical trajectories (all of these structured by, and reproducing structures of, power) such that language does not independently and thoroughly constitute our world" (p. 706). Therefore while it is legitimate to say that the birth and upbringing of a child marks a significant change in family dynamics; it also needs to be pointed out that the child's birth often leads to the formation of a 'motherhood constellation', which places the mother in a position to mentally give importance to all issues related to motherhood, with new boundaries are set as the family composition changes (Borghini et al., 2006). This expectation reinforces the symbolic dimension of the different roles of fathers and mothers, and in this respect, language forms the basic building blocks of a social system (Luckmann 2008, 277).

This becomes entrenched in society as it leads to the communication construction of a collective memory where expectations about mothers are seen as taken-for-granted realities and makes these realities seem to be an invention passed down over time "consciously designed to deal with present problems" (Schwartz 1991, p. 221). Indeed, in the context of working mothers, numerous studies (e.g. Betz and Fitzgerald, 1987 in Whitmarsh, 2007; Ezzedeen and Ritchey, 2009; Brown, 2010) show that many mothers choose to interrupt their careers by choice in order to dedicate more time to caring for their children; yet if fathers do so, it may be assumed that such a decision would be taken for a set of reasons different to those of working mothers. It is likely for this reason that in many societies, mothers often find themselves constrained to modify their career aspirations to enable a more compatible match with their family responsibilities (Jackson and Scharman, 2002; Whitmarsh, 2007; Ezzedeen and Ritchey, 2009; Brown, 2010; Pas et al., 2011; Mirick and Wladkowski, 2018).

This is primarily in the face of the shifting of the traditional motherhood ideology, so "women are expected to work at least a few days per week, yet they are also expected to mother intensively when at home" (SCP, 2008 in Pas et al., 2011). It may, however, be argued, based on the work of anthropologists like Sherry Ortner (see Ortner, 1974), that women's physiology and reproductive functions make her appear closer to nature whilst men look to adapt to their environment and therefore appear to be closer to broader cultural participation. Women's activities are consequently restricted to the domestic sphere, while men are licenced to go wider afield, becoming more prominently inserted in public spaces rather than private ones. The mother is also biologically better equipped to be the person rearing the children, implying that, particularly from a social constructionist perspective, culture, and society itself, may even lead to the generation of an 'internal conflict' for working mothers, since having a demanding career may be perceived as incompatible with being a 'good' mother. However, this does not negate that, particularly from contemporary Western societies' perspective, there are several advantages to working mothers retaining their work and their career. Besides the financial benefits derived from salaries, a working mother can be an inspiration for her children (Borg, 2011). Pas et al. (2011) show that a group of female doctors, who were also mothers, saw their work to enable them to be more self-resilient and independent, thereby serving as effective role models to their children.

On the other hand, conflicts between work and family life have been associated with several negative consequences, both individually and for organisations themselves. These include higher levels of dissatisfaction at work, work distress and adverse reactions to the extraorganisational stressors if a personally satisfying work-life balance is not achieved (Mirick and Wladkowski, 2018). To make matters worse, in some countries, women tend to avoid availing themselves of family-friendly policies out of fear of losing their jobs (Cabrera, 2009). It is also possible that people do not avail themselves of the resources available out of shame in some cultural contexts, although this is not necessarily universal. For instance, Herman and Lewis (2012) explain that making extensive use of a childcare centre is still frowned upon in countries 
such as Germany, even though it is common practice in France. A possible interpretation of this is that French mothers take career continuation upon their transition to motherhood for granted. The distinction that Herman and Lewis are drawing between Germany and France accentuates that the dilemmas that some working mothers may face about availing themselves of childcare facilities are not their personal issues, thereby requiring self-confidence to deal with, but rather may be more widely located in social contexts that may be oppressive, and thereby are political (Hanisch, 1970). Within the Maltese context, the demand for childcare facilities is increasing. However, this is not necessarily indicative of working mothers being in a better position to give priority to their careers, since it could be triggered by the rise of immigrant populations in Malta and also the economic necessities of certain families who may use childcare facilities because they feel constrained to do so as both parents have to work in order to make ends meet.

Previous studies in Malta on occupational issues do not focus specifically on the issues of working mothers, even though countering gender discrimination has been the subject of attention from both academic and policy perspectives. The National Council for the Promotion of Equality (ncpe.gov.mt) has lobbied for further gender equality. Its efforts have likely borne fruit since even though Malta is seen as lagging the EU average in gender equality, it is one of the countries with the largest improvement over a decade - based on the results of the 2020 Gender Equality Index results. The University of Malta runs a Centre for Labour Studies, which, as stated on the university website, has as one its aims that of promoting social dialogue, active involvement and the effective participation of both male and female workers, and their representatives, in specific workplaces, and labour policy more generally.

\section{The approach adopted}

This paper aims to provide insights into working mothers' lives in Malta. It promotes an understanding of working mothers combining the commitments associated with family life with working life. The paper adopts a phenomenological approach that blends with its social constructionist orientation. Moustakas (1994) believes that the phenomenological approach captures the essence of people's individual experiences by synthesising them into a collective description of the phenomenon being studied. From a social constructionist paradigm, a study focused on how women construct their identities as family members, mothers, workers, colleagues, and people with a possible position in workplace hierarchies is a highly subjective one. As Gergen and Gergen (2003) explain, "social constructionist inquiry is principally concerned with explicating the processes by which people come to describe, explain, or otherwise account for the world (including themselves) in which they live" (p.15). This implies that, from a social constructionist paradigm, different people are liable to experience these roles and how they combine these roles differently. However, the same person will define them and redefine them differently in different phases in life. In addition, these ways of defining roles are bound in political discourse. Burr (2003) writes that "the popular representation of the good mother as one who spends time with her children when they are young and who sacrifices her own needs to theirs (effectively) helps to keep women out of full-time employment and ensures their economic dependency on men" (p. 123). In the light of this, as Creswell $(2013,2014)$ explains, a phenomenological study looks beyond how individuals construct meaning of their own experiences, focusing on how people report how they experience events differently within the extenuating circumstances in which they find themselves.

Historically, Edmund Husserl is believed to have founded phenomenological research (Moustakas, 1994). Husserl believed that through actively engaging with a small number of individual research participants, who are actively associated with a phenomenon of interest, it would be possible to understand their lived experiences. McNamee and Gergen (1999) share 
this aspiration to understand people's experiences using dialogue. One aspires to understand the other by broadening one's understanding of reality without losing sight of oneself. McNamee explains that "dialogue is a process of holding firmly to one's position while maintaining a curiosity and respect for another's very different position". One's position can be more than one position, each competing with the other to be given attention, thereby pointing to the notion of multiple selves.

Moustakas (1994) recommends that phenomenological research carefully follow a series of procedures, and an adaptation of Moustakas' approach has been adopted in this paper. First, Moustakas suggests commencing from developing a topic or problem that is liable to have deep personal meaning for those experiencing the phenomenon, as would be the case for working mothers, who must deal with the different demands of their homes and their workplaces. Moustakas then suggests an extensive literature review that would enable researchers to advance their knowledge on the subject they are studying and offer insights from different social, cultural, and temporal perspectives. Once the literature review has been completed, the researcher would then need to construct a set of interview questions designed to guide the interview process, using meta-reflection to understand one's different positions about what being a working mother infers. In the case of this research, this process was further enriched by discussions between the two researchers that also took into consideration their different gender and that their families were in different stages of development. They also used bracketing in assembling the questions to reduce bias. When brainstorming potential questions that they could ask, the researchers examined how their personal awareness might enter the research. Because of this meta-awareness, they put in efforts to suspend their own understanding so that the participants' voices would be elicited - as far as possible. Finally, Moustakas suggests that the schedule of questions would be flexibly put to interviewees when conducting the interviews to ensure that their perspective is captured as far as possible; and allow them to add further data that they considered relevant, thereby enabling them to a thick representation of reality to ensue. In other words, besides having "the purpose of obtaining descriptions of the life world of the interviewee in order to interpret the meaning of the described phenomena" (Kvale and Brinkmann, 2008, p. 3), semi-structured interviews have the additional advantage of making greater use of "knowledge-producing potentials of dialogues" by allowing room for the interviewees to follow-up on whatever points they wish to (Brinkmann, 2013, p.21).

In the final stage of the research, Moustakas suggests that the researcher analyses the data, synthesising the discovered meanings to determine the essence of the experience. This called on the researchers to explore the subjective understanding of an experience and any social, cultural, and historical ties to it, thereby enhancing its phenomenological validity. In the case of the research undertaken, this implied that the researchers needed to be vigilant to prevailing gender discourses and outlooks and political factors that may have enabled or impeded working mothers from achieving their aspirations. In this way, it was more likely that the research would reflect the "fluidity and complexity of ways of performing mothering practices alongside professional work .... where there are deeply embedded structural constraints but (there is) also some space for a personal agency" (Herman et al., 2012, p.3).

According to Ponterotto (2005), the interaction between the interviewer and interviewee is crucial to uncover 'meaning' which needs to be brought forward through deep reflection. This lends itself to the adoption of a qualitative research design that gives rise to an analysis of how the participants' account is embedded in the inter-relationship between language, culture, and society; and how it is this embeddedness that enables it to have meaning. Adopting a qualitative research design enables an in-depth understanding of the participants' personal lives to be rendered. Hakim (1987) defines qualitative research as "a direct window on the lives of the participants ... (that) offers richly descriptive reports of individuals' perceptions, attitudes, 
beliefs, views and feelings, the meaning and interpretations given to events and things, as well as their behaviour" (p.211). From a social constructionist point of view, where social reality is seen as emanating from the interactions between social actors and their historical and cultural contexts (Burr, 2003), qualitative research makes it possible for explorations to be undertaken; thereby, in the case of the current research undertaking, allowing the analysis to be focused on the women's subjective appreciation of their own lived experiences, including their studies and careers, as well as their personal lives and corresponding expectations. Field notes, later utilised to inform the analysis, referred to the tone of voice, facial expressions, and the researcher's thoughts. Each interview was recorded and transcribed verbatim to enhance confirmation and credibility (Lincoln and Guba, 1985; Guba and Lincoln, 1994) whilst preserving interviewee anonymity. To ensure that consistency prevailed throughout the research collection part of the analysis, it was decided that all research interviews would be conducted by the female researcher only. It was presumed that the participants, who were all female, might have answered questions differently had they been interviewed by the male researcher. The participants were selected utilising a snowball sample, and seven interviewees participated. It so happens that all the participants live with their partner (male), which may reflect that most families with children in Malta are heterosexual couples. The following table provides some demographic information on the interviewees:

\begin{tabular}{|c|c|c|c|c|c|c|}
\hline $\begin{array}{l}\text { Fictitious } \\
\text { name }\end{array}$ & Occupation & Age & $\begin{array}{l}\text { Marital } \\
\text { status }\end{array}$ & $\begin{array}{l}\text { Number } \\
\text { of } \\
\text { children }\end{array}$ & $\begin{array}{l}\text { Ages of } \\
\text { children }\end{array}$ & $\begin{array}{l}\text { Highest level of } \\
\text { schooling }\end{array}$ \\
\hline Christabelle & $\begin{array}{l}\text { Head of } \\
\text { School }\end{array}$ & 41 & Married & 2 & 7 and 5 years & $\begin{array}{l}\text { Post-graduate } \\
\text { diploma }\end{array}$ \\
\hline Mary & $\begin{array}{l}\text { Childcare } \\
\text { owner }\end{array}$ & 54 & Married & 2 & 27 and 22 years & Master's \\
\hline Rachel & $\begin{array}{l}\text { Director } \\
\text { and senior } \\
\text { lecturer }\end{array}$ & 42 & $\begin{array}{l}\text { Divorced, } \\
\text { in a } \\
\text { relationship }\end{array}$ & 1 & 10 years & $\mathrm{PhD}$ \\
\hline Astrid & $\begin{array}{l}\text { Family } \\
\text { services } \\
\text { manager, } \\
\text { ex-Director }\end{array}$ & 48 & Married & 2 & 16 and 12 years & $\begin{array}{l}\text { Undergraduate } \\
\text { degree and a } \\
\text { Master's degree } \\
\text { in progress }\end{array}$ \\
\hline Carol & Head of HR & 42 & Married & 1 & 9 years & Master's \\
\hline Ritienne & $\begin{array}{l}\text { Deputy } \\
\text { Director }\end{array}$ & 41 & Separated & 2 & 11 and 14 years & $\mathrm{PhD}$ \\
\hline Rose & CEO & 61 & Married & 1 & 32 years & Master's \\
\hline
\end{tabular}

Figure 1 Demographic data of the interviewees.

Thematic analysis was used to analyse the data generated by the interviews. Based on previous research that the researchers had undertaken, thematic analysis was ideal for identifying, analysing, and eliciting patterns (themes) within data. In other words, the meaning that emerges comes from the data; any patterns in the responses given emerge out of the data rather than being imposed on it prior to the analysis (or collection) of the data (Strauss and Corbin, 1990). The analysis involved several steps, including reading and re-reading the transcripts, comparing, and sorting data and coding any observations and annotations comprised in the field notes. The codes were then examined, paying close attention to context so that common patterns and trends were accumulated. After a vigorous process of checking, rechecking, reflecting, and 
revising the links between the knowledge brought forward in the literature review and the data generated through the data sets, assertions and generalisations were then drawn out as theories or constructs were examined in light of relevant bodies of theory (Miles and Huberman, 1994; Miles, Huberman and Saldana, 2014; Roulston, 2014), following on from intensive discussions between the researchers.

\section{Findings}

\section{Family support}

All the interviewees expressed satisfaction and fulfilment in their role at work, and all of them felt that they were living up to their potential. Nevertheless, the participants reported that things have not always been so. Most said they had to find ways of actualising themselves at work, without, as much as possible, failing to look after their families. Astrid said she waited for her children to grow up and be independent and said that now that she was free of certain obligations since her children were older, she could give more importance to her job and derive satisfaction from it. Likewise, Rose speaks about her need to contribute and derives a heightened sense of self-worth from doing so. She said, "I like the challenges my work gives me, the fact that I am contributing to improving people's lives, even though I am in the background, but what I do indirectly helps people's lives and my personal growth." Similar to what Ezzedeen and Ritchey (2009) found in a study on working mothers, having another role apart from that of a mother makes it possible for them to say that they feel 'complete'. Ritienne explains this by saying that "being a career woman is part of who I am, a part of my identity. It has helped me become more confident, assertive, and more aware of the realities around us. It has provided me with opportunities not only to improve myself personally and professionally but also to improve the quality of the life of my children", Rose, who likes to think she is on the brink of retirement, yet, says that she does not cease to take on new projects, talks about her yearning to put her abilities and experience to practice: "Look, I always say that if society did not want me to use my potential and push through and get involved in a thousand things, all that it was to do was to deprive me of education. The fact that I had an education, sitting back was just not good enough for me. I felt that my contribution had value. If I had not contributed and involved myself the way I did [...], I would probably be somewhere banging my head against the wall [...]. I would be a very depressed person [...]. My work gives me great satisfaction."

On the issue of balancing work life and family life, Ritienne said: "my children are proud of me and look up to me...It gives me personal satisfaction as I thrive when there is a challenge, and thus I am able to feel happy in my everyday life. This impacts positively on me as a parent as the children can see that I love what I do. It sets a good example for them, too - they have seen me working hard and know that hard work pays off. They can also see that despite the pressures of work, they always come first..." However, balancing work and family life does not come without costs, as Carol explains when she says, "you have to make a choice. If you want to satisfy all the demands of the family, frankly, one should not go for a high-flying career. I know very well it does not work". Ritienne also cautions against over-stressing herself by working, even though she believes she has "found the right balance" for herself. She says, "My suggestion to all women is: if you want a career and you have a family, know what it will cost you. If a woman feels that it will be too demanding and will create lots of stress and conflict with family life, my strong advice does not to go for a career. In the end, both will suffer because the psychological stress that you and those around you will have to endure will affect you dearly".

All the interviewees mentioned studies as part of their working life. They all appeared keen to make studying as non-disruptive as possible to their roles as mothers and their family life. Astrid explained that she had delayed starting her master's degree for some time. She explained that 
not furthering her education earlier is her most profound regret, but "it was simply not possible to be in a management position, with those hours, and study simultaneously, with the kids. She said that the turning point had come about last year when she had said to herself, "the children are growing," which led her to permit herself to enrol for her degree via distance learning not to disrupt her family. The same can be said for Mary, who waited until her children were "old enough with my daughter at sixth form" to do her Masters' degree. She also went for an online course rather than one based on face-to-face learning.

Some of the participants described more intense negative feelings even though they evidently put these aside to fulfil their career ambitions. Rachel described her heartbreak and feelings of guilt when she had to go abroad for five days for a meeting relating to her studies toward her doctorate. She vividly describes saying goodbye to her son, who was still a baby. However, some of the participants decided to turn down opportunities for career advancement. Rose, for example, refused two scholarships for her doctorate to be present for her daughter, who was doing her end-of-school exams. She said, "and yes, I regret it [...]. I regret it because it was a difficult, crucial period in my daughter's life, in her studies, and I felt that I should not impose my further hurdles against her advancement. It was a crucial time. My place was here in Malta [not abroad]. I reasoned that my daughter did not ask me to come to this world. It was my doing, and so, my responsibility to look after [...], but I cannot say that I am not hurt, that I am not hurt still, since I did not pursue my studies at a doctoral level then, and I find it almost impossible to start now."

Most of the interviewed women have taken a career break or slowed down their careers either to attend to their children full-time or at some crucial period in their children's lives. Carol explains that "I stopped for two years to take a break because my child needed me, and I stopped my career for a while. In the end, I stopped; the father remained where he was. It is always the mother who has to give up". Rachel explains that in the first five or six years of her son's life, she opted not to go abroad on work-related trips, which may have negatively impacted her reputation in terms of publications.

Astrid recounts how, in addition to parental leave, she held a position as a Director for almost five years just because the hours were "convenient...for my children... it was convenient as it was more structured, with more fixed hours" despite "being desk-based and not really what I like doing... deep down I knew that I did not belong there" while Christabelle refused the position of a Head of School twice because of family responsibilities and only finally accepted it as she was guaranteed the possibility of stepping down at any time if she wanted to.

Similarly, Mary also spent a few years at home to raise her kids and later waited until her children "were old enough to be a little independent, so if anything crops up, they will manage to do things on their own" until she opens up her own Childcare Centre. At the same time, Ritienne stopped working completely for four years when her two kids were young. Furthermore, she worked in the same school as her children for many years until she "could afford to work different hours when they started growing up".

\section{Spousal and parental support}

The participants also mentioned the support of their partners and spouses as a vital feature of their working lives and careers. Without that support, they all admitted that, as Ritienne put it, "the road would have been distinctively harder since I would have felt all alone." When asked if the daily struggle to maintain a healthy work-life balance was the same for fathers, Carol explains, "No, it is not the same. "Fathers still do not get it. For them, going to work and spending the whole day there and letting mothers deal with the rest is something I have seen all over the world. I believe it will take another century to see real change in this, should it ever 
happen." Using similar reasoning, Rose says: "No, obviously not! Rather we praise fathers for coming to work! No. We, socially, still have this major distinction where we expect this from mothers and expect something else from fathers. For example, if my husband had had to spend some time at home with our daughter while I was abroad, he would almost be seen as someone to be pitied! His own daughter! They would think, "he should have his wife, and his wife should be more present...". Ritienne reasons out that the struggle for fathers depends on the extent to which they desire to be present in their children's lives, whilst Astrid and Mary believe that it all has to do with the arrangement struck between the parents themselves. Both Astrid and Mary have had the support of their spouses in their career-related and family-related decisions, with Astrid depicting that "he [husband] helps me in my work and the decisions we make and with the kids, but deep down I still think that the load is on me. I still remain the person responsible for the children." Astrid explained further that "he [my husband] helps me in my work and the decisions we make and with the kids, but deep down I still think that the load is on me, even though if a meeting cropped up and I ask him to pick them up, he finds a way out, so I always remain the person responsible for the children". These situations are analogous to those of the female managers interviewed in the study by McKie and Jyrkinen (2018). One of the managers interviewed in this study said "We should be pushing for partners to do more and take equal responsibilities so that you get the two partners devoting [time to care] [...] sacrificing less on both sides of the parenting or care partnership".

Christabelle and Carol firmly believe that it is the work commitment they went in for that caused them to jeopardise their duties as mothers, with Christabelle saying, "I have guilt feelings all the time $[\ldots]$ a lot $[\ldots]$ all the time $[\ldots]$ everyday...that I am not doing my job well as a mother due to this job [...] every day [...] all the time [...] huge guilt feelings every day $[\ldots]$ and I am very worried about this." Carol confirms the existence of this struggle claiming that "Of course it does [clash]. Those who say that it does not are not true to themselves. Senior leadership roles are very demanding, and one has to be very clear of the demands they make and the toll they take on our lives. Many sacrifices and compromises have to be made daily to be successful at work and to juggle with work-life and work-home balance successfully". Astrid recounts how on certain days, work takes over, so she makes up for this by dedicating more time to her family on days when the workload is lighter. Similar concerns about work commitment have been raised in a study by Brown (2010), with mothers declaring having missed out on promotions due to moving to part-time status, hence, losing access to career advancement opportunities or because "they [promotions] would have involved more time commitment than I felt comfortable giving while being a mother to my children." Christabelle said that her husband would feel that "he would be less of a man if he gave up his full-time job to dedicate more time to the home, bringing up financial reasons for not doing so, even if I had to earn more than he does."

A further factor that was intertwined with spousal support was support from extended family members. All the interviewed mothers said that they got support from their immediate family members, particularly their parents. For example, Carol describes her parents as "the driving force behind me", whilst Rose explains that "If I had not my mum who was available and supported me, I would not have done it". Ritienne says that "my family helps a lot - the kids go to my parents' house after school - so, in that way, they get a good meal and a safe place to do their homework until I pick them up".

\section{Support at work}

The participants mentioned various ways in which they felt supported at work. Carol explained that she received a degree of practical empowerment, rather than sole empathy, from her managers at work. She says, "I am lucky that I have a CEO who is mindful of family commitments, and he encourages me and allows me much flexibility. He knows I will deliver. 
However, I must run a department of 20 people, and I need to be there to drive things. However, had it not been for my flexibility, I would not manage to do the things I do." Astrid says that she owes a lot to her colleagues, who found a way to step in for her to maintain her position as a director, particularly when she had taken a year off as parental leave. This motivated her further to invest time and energy into her work. Rose also enjoyed support and encouragement from her managers and colleagues; and spoke about how she was involved in decisions that enabled her to meet work and family commitments. She said that her managers had asked her questions like "what would be the best way to do this? What would suit you best?"

Gravitating against this type of empathy were gender stereotypes and associated stigmas. The associated adverse perceptions about women in leadership positions have been seen to prevail in many societies and investigated in various studies (example; Ching-Yim and Harris Bond, 2002; Mostafa, 2003; Cortis and Cassar, 2005). The participants in this study did not believe that they had been harassed at work; however, Carol said that initially, she thought she was not trusted at the workplace. She said she used to avoid mentioning motherhood and family at first but only mentioned it once her colleagues at work had got to know her. Having said this, Mirick and Wladkowski (2018) point out that there may be an unspoken consensus among male coworkers that one "should not emphasise motherhood and family, talk about it, or let it interfere with their work," showing the possible existence of a cultural script separating work life from family life. Conversely, Ritienne explained how "taking up a managerial position was highly contested by people in my immediate family - the reason being that there is always judgement against a mother who seems to value her career." This made it important for her to feel comfortable when working, and she mentioned that she was glad she was not put down at work because she was a woman. Even though eliminating discrimination and eliminating inequality could be a boost for economic growth and to diminish inequality (Wayne, 2017), some of the participants mentioned that they were presented with several challenges at the workplace simply because they were working mothers, but then took it upon themselves that they had the onus to adapt. True to this line of reasoning about adapting to workplace situations, Gavin et al. (2003) suggests that one's character is key to the effectiveness and health of an executive. All the interviewed mothers displayed various skills that convey an ability to have good relations with colleagues.

\section{Discussion}

The participants' narratives were driven by the fact that they were working mothers and people who prioritised work and family. However, the emphasis on feeling fulfilled and the heightened sense of self-worth that they derived from having an education shows that not only the women's lived experience is constituted, as a construction, with a specific cultural and historical background that reinforces high education levels but also as something that was somewhat expected of them if they were to self-actualise themselves and thereby independent of their volition, at least to a certain degree. Conrad and Baker (2010) observe that "the meanings of phenomena do not necessarily inhere in the phenomena themselves but develop through interaction in a social context" (p.65). Likewise, while most participants managed to balance work, studies and being mothers, others decided not to pursue their studies. However, advancing in their studies reflects a particular social context where advancement in studies may open the doors to potential career progressions.

Thereby the regret at being unable to further studies may betray a gendered discourse where an implicit reference is being made to the domination of one gender over another; since men may find achieving career goals far easier since they are less constrained by family commitments, and thereby this sense of regret is a socio-cultural construction linked to the power structures of society. In effect, almost all the interviewees mentioned understanding husbands or partners. 
Nevertheless, they (as mothers) still undertake the major load of responsibility for the children and the household chores, including all the planning and organising activities associated with raising a family. As Astrid put it, "motherhood and work clash mostly because as a society we are still far behind in terms of work expectations, work ethic and demands - for men, being a workaholic is still thought to be positive, whereas I strongly believe that society would be much better if more family-friendly measures were in place. More than the kind of job responsibilities, the lack of flexibility sometimes negatively impacts my role as a mother - I do my best to juggle and find a good balance; however, it is never enough. Men are somehow expected to juggle differently."

When the interviewees mentioned that they derived continuous support from their parents, who in turn volunteered to take care of their grandchildren while their daughters tended to work responsibilities, it seems that this further cemented the discourse that holds mothers responsible for their children's well-being, development, and successful adaptation in life. The participants were more likely to reach out to their own mothers for support than their husbands. This could reflect guilt and shame that they sometimes reported experiencing because of working and studying, rather than simply feeling more comfortable leaving the children with their own parents. If so, the disabling experiences of dominant discourses around working mothers may never have been addressed or challenged since they may not have been brought into conscious awareness. It transpires that, in this study, all the participants had children who did not have disabilities and thereby did not show the signs of distress that parents of disabled children experience. Also, none of the mothers was disadvantaged socio-economically, and this is likely to have had a positive bearing on family functioning.

Support and empowerment from the participants' superiors and, in some cases, colleagues at work impacted the interviewees significantly. The participants believed that balancing family and work proves to be extremely difficult and requires constant planning and organisation, time management, perseverance, and resilience. A particular point worthy of mention is that none of the interviewees ever mention sending their children to any formal Childcare Centres, even though there has been a recent surge of provision of this facility both by the state and by private providers in Malta. When the researcher purposely brought up childcare provision toward the end of the interview, the participants did not consider childcare as a feasible option, this possibly showing that they had their parents and support network to turn to. Christabelle believes that childcare is not an answer since "children miss out a lot when the mother is not present". However, both Astrid and Rose mentioned personal shame as the reason for not sending their children to childcare, explaining that they believe that society does not always approve of a mother who sends her children to childcare. Rose explains that "social judgement is still there. If a mother had a baby and returned to work, we still have that big question mark. It seems like we do not have the space to say, "it is her choice." Making it clear that she was referring to other people, she then added that "an unhappy mother is not the best for any child. So, we need to understand that if a mother feels self-actualised at the place of work, picks up her children from childcare, and takes care of them in that way, then this is fine. However, society is not there yet". What Rose was saying is that for there to be a greater sensitivity to the concerns of working mothers, society must simultaneously acknowledge a mother's contribution towards society through motherhood itself, through her potential contribution to organisations and the labour force as a whole, and for her need to actualise herself in her place of work - while taking into consideration her personal circumstances and the wider societal influences that have the potential to leave an impact on how she perceives and frames the resources that are available to empower her to reach her personal goals. 


\section{Conclusion}

\section{Main inferences}

Across the interviews, the mothers' innate drive to prioritise their children was evident. All of the interviewees seem to have shaped their careers or studies around family responsibilities, with all but one opting for career breaks when their children were still young. Despite the possible negative repercussions in their careers, such a decision was never regretted; somewhat, it was perceived as an investment in their children. Nevertheless, all of the interviewees chose to pursue self-actualising roles at work at some point or another, and all of the interviewees found ways to engage in further studies. Almost all interviewees mention understanding husbands or partners, yet, it seems that the mothers still undertake full responsibility for the children and the household chores, including all the planning and organising. Issues were also raised as to why the mother has to jeopardise her career through career breaks or similar arrangements rather than the father. The patriarchal culture and the social judgement towards mothers who decide to pursue their careers have also featured prominently.

All interviewees derived continuous support from their parents, particularly in taking care of their grandchildren, while their daughters tended to work responsibilities. Support and empowerment from their superiors and, to a lesser extent, colleagues at work left a considerable impact on the interviewees. Whilst the majority also mention hurdles and challenges posed by their superiors or colleagues, these did little to belittle their quest to live up to their potential at work. In terms of the latter, all Interviewees express pride and fulfilment from their role at work; however, this does not come without many sacrifices and much stress, especially since they all seem keen to fulfil both work and motherhood duties.

Alas, balancing family and work proves to be extremely difficult and requires constant planning and organisation, time management, perseverance, resilience, and completely sacrificing one's time for hobbies or similar interests. In fact, a participant primarily questions whether assuming such a role at work is worth the negative impact it is leaving on her family, whilst another claims that she has made a conscious decision when pursuing such a high-flying career, that it may compromise her motherhood responsibilities.

\section{Recommendations}

Whilst attaining a work-family balance is very difficult, if not next to impossible for some, family-friendly measures at work, such as flexible hours or teleworking, do ease this plight. However, such measures need to be standardised, regulated, and monitored by sound policies, which measure work by 'output' rather than the number of hours spent.

A further consideration is that young working mothers are millennials born between 1980 and 2000. Their name derives from that they are closest to a new millennium and live in a "digital age". Briffa (2020), while focusing mainly on the hospitality industry, points out as young employees, Maltese Millennials prefer a work-leisure balance from the start and demand different working conditions and remunerations than those that older generations were likely to be ready to settle for. In Horizon (2020), gender is a cross-cutting issue. It is mainstreamed in each of the different parts of the Work Programme, thereby reinforcing a mentality where women and men's needs and behaviours are considered.

Again, such measures would, perhaps, attract greater female engagement in the workforce, yet would do little to promote mothers' self-actualisation at work. As pointed out in the report by McKinsey and Co. (2021), companies should communicate what is expected of employees and 
what it means to have an inclusive culture. The report points out that building this thinking into company values is a good start. However, organisations would benefit from articulating the specific behaviours and actions that promote inclusion. This implies that more supportive measures and structures need to be set up and a degree of flexibility afforded to mothers who wish to move further in their careers. These need to be coupled with mentoring, role models and empowerment initiatives that facilitate mothers to succeed both at their role at work and motherhood, without compromising any of the two. Juggling between such roles is undoubtedly not a "walk in the park", but mothers are more likely to succeed given the necessary support, the space, and the time (beyond the rigid office hours).

Engaging in roles of responsibility and giving their best in them whilst the children are growing up tend to infringe upon family responsibilities, especially when the parents do not see formal childcare services as the answer or in situations where a lack of support from family members prevail. What might help mitigate the situation is the provision of such jobs on a reduced or part-time basis, although these might not always be feasible. Tailoring office hours at par with school hours may also facilitate this. What would make a difference for mothers, in general, in terms of their work-family balance, is the empathy and support their workplaces afford, and these do include not only organisational policies but also the organisational culture and the attitudes of the superiors themselves (Ezzedeen, 2009; Brown, 2010).

Finally, society must simultaneously acknowledge a mother's contribution towards society through motherhood itself, her potential contribution in organisations and the labour force, and her need to actualise herself in her place of work and give opportunities and support her decision to do so just like society does for fathers.

\section{Limitations and opportunities for further research}

The limited contact time between the researcher and the interviewee may have translated into less data being gathered than had more time been available. Furthermore, the anecdotes of the children, partners or spouses, and other immediate family members of the interviewees would have provided a complete picture of their lives and produced more reliable results, particularly in terms of triangulation. The interview responses cannot be extrapolated to all mothers in executive positions. In other words, the small sample size of the participants taking part in the study hinders the ability to generalise and reproduce the findings beyond the constraints of the sample.

On the other hand, the complexity of women's family balance and career success has been recognised but inadequately studied (Ezzedeen, 2009; Brown, 2010). Hence, similar studies, preferably on a larger scale, would undoubtedly yield valuable data upon which policymakers and organisations can act. Such studies may take different forms, including cohort or longitudinal studies. Some variables to consider when investigating mothers' work-family balance may include; the different stages of the children's lives, the varying degrees of support available to the mother, a changing of job for the mother or father and/or a changing of marital status.

Other studies may focus on single mothers as another cohort. Comparative studies may also be held with fathers, possibly yielding fruitful data to inform national policies aimed at both parents and not only mothers. Finally, an equally exciting study would entail exploring the experiences of women who dismissed motherhood altogether to pursue their careers and/or studies exclusively.

Valuable data may also be obtained from 'mumpreneurs' who take pride in a "sense of control they had over their work which enabled them to fit hours around other responsibilities", yet experience "stressful times trying to combine the business with motherhood" and "tension when 
their espoused reasons for setting up a business - to be available for their children - conflicted with how they were allocating their time" (Pace Frendo, 2017).

Finally, it would also be helpful to compare gender-neutral and female-dominated careers, especially since the study by Whitmarsh (2007) showed that the difference in career "appeared to be a critical determinant in the decision to blend a career with motherhood or to complete them sequentially". In this light, comprehensive studies involving the feasibility, implementation, monitoring, and tangible results of family-friendly measures need to be conducted nationally and within organisations. As is evident from the responses of the surveyed participants, the mere provision of flexible hours, for example, would simplify the lives of many employees. Nevertheless, the frameworks and policies informing such measures need to be supported with authentic, concrete research, particularly on a local scale.

\section{References}

Aveling, N. (2002). 'Having it All' and the Discourse of Equal Opportunity: Reflections on Choices and Changing Perceptions, Gender and Education, 14: 3, 265-280.

Baber, K. M. and Monaghan, P. (1988). College Women's Career and Motherhood Expectations: New Options, Old Dilemmas, Sex Roles, 19: 3, 189-203.

Bailey, L. (2000). "Bridging Home and Work in the Transition to Motherhood: A Discursive Study." European Journal of Women's Studies, 7: 1, 53-70.

Bielby, D. D. and Bielby, W. T (1984). Work Commitment, Sex-Role Attitudes and Women's Employment. American Sociological Review, 49, 234-247.

Bhattacharyya, R. (2009). Examining the Changing Status and Role of Middle Class Assamese Women: Lessons from the Lives of University Students. PhD thesis, Newcastle University, UK.

Bhattacharyya, R. (2016). "Balancing Motherhood and Career in STEM Jobs." Space and Culture, India, 3: 23, 28-31.

Borghini A, Pierrehumbert B, Miljkovitch R, Muller-Nix C, Forcada-Guex M, Ansermet F. Mother's attachment representations of their premature infant at 6 and 18 months after birth. Infant Mental Health Journal. 2006;27(5):494-508.

Briffa, Nicole (2020) The dichotomy between perceived and actual working conditions in the hospitality industry in the 2020's; the millennial perspective. Unpublished Bachelor's Degree Thesis, University of Malta.

Brinkmann, S. (2013). Qualitative Interviewing: Understanding Qualitative Research. New York: Oxford University Press.

Borg, A. (2011). Thinking of going back to work? Employment and Training Corporation (ETC). Retrieved from https://jobsplus.gov.mt//publication-statistics-mt-mt-en-gb/policies/fileprovider.aspx?fileId=1262 on $12 / 04 / 18$.

Brown. LM (2010). "The relationship between motherhood and professional advancement: Perceptions versus reality." Employee Relations, 32: 5, 470-494.

Brus, C. P. (2006). Seeking balance in graduate school: A realistic expectation or a dangerous dilemma? New Directions for Student Services, 115, 31-45. doi:10.1002/ss.214.

Burr, V. (2003). Social constructionism (second edition). London: Routledge.

Cabrera, E. (2009). "Fixing the leaky pipeline: five ways to retain female talent", People and Strategy, 32: 1, 406.

Ching-Yim, P. \& Harris Bond, M. (2002). "Gender stereotyping of managers and the self-concept of business students across their undergraduate education", Women in Management Review, 17: 8, 364-72.

Conrad, P. and Barker, K. (2010) The Social Construction of Illness: Key Insights and Policy Implications. Journal of Health and Social Behavior, 51, S67-S79

Cortis, R. and Cassar, V. (2005). "Perceptions of and about women as managers: investigating job involvement, self-esteem and attitudes." Women in Management Review, 20: 3, 149-164.

Creswell, J.W. (2013). Qualitative inquiry \& research design: Choosing from five approaches. (3rd ed.). Thousand Oaks, CA: Sage.

Creswell, J.W. (2014). Research design: Qualitative, quantitative, and mixed methods approaches. (4th ed.). Thousand Oaks, CA: Sage.

Elvin-Nowak, Y. and Thomsson, H. (2001). Motherhood as idea and practice: A discursive understanding of employed mothers in Sweden. Gender and Society, 15: 4, 407-428.

European Institute for Gender Equality. (2018). Gender equality index 2017: Malta. EIGE

Ezzedeen, S. R. and Ritchey, K. G. (2009). "Career advancement and family balance strategies of executive women." Gender in Management: An International Journal, 24: 6, 388-411. 
Gavin, J. H., Cooper, C. L., Quick, J. C. \& Quick, J. D. (2003). “A spirit of personal integrity: the role of character in executive health", Organizational Dynamics, 32: 2 165-79.

Gender Equality Index. European Institute for Gender Equality (2020) Accessible at: https://eige.europa.eu/gender-statistics/dgs

Granrose, C. S. and Caplan, E. E. (1996). Work-Family Role Choices for Women in their 20s and 30s: From College Plans to Life Experiences, Westport: Praeger.

Guba, E. G. \& Lincoln, Y. S. (1994). Competing paradigms in qualitative research. In N. K. Denzin \& YS. Lincoln (Eds.), Handbook of qualitative research (pp. 105-117). Thousand Oaks, CA: Sage.

Hakim, C. (1987). Research design: Strategies and choices in the design of social research. London: Allen \& Unwin.

Hanisch, C. (1970). The personal is political. In Firestone, S. \& Koedt, A. (Eds.) Notes from the second year: Women's liberation. New York, NY: Radical Feminism.

Hays, S. (1996). The Cultural Contradictions of Motherhood. New Haven, CT: Yale University Press.

Herman, C. \& Webster, J. (2010). Taking a lifecycle approach: redefining women returners to science engineering and technology. International Journal of Gender Science and Technology, 2: 2, 179-205.

Herman, C. and Lewis, S. (2012). "Entitled to a Sustainable Career? Motherhood in Science, Engineering, and Technology." Journal of Social Issues, 68: 4, 767-789.

Hilbrecht, M., Shaw, S., Johnson, L. and Andrey, J. (2008). I'm home for the kids: Contradictory Implications for work-life balance of teleworking mothers. Gender Work and Organisation, 15: 5, 454-476.

Hoffnung, M. (2004). "Wanting It All: Career, Marriage, and Motherhood During College-Educated Women's 20s." Sex Roles, 50: 9, 711-723.

Horizon. (2020). Promoting Gender Equality in Research and Innovation https://ec.europa.eu/programmes/horizon2020/en/h2020-section/promoting-gender-equality-research-andinnovation

Jackson, A. P., \& Scharman, J. S. (2002). Constructing family-friendly careers: Mothers' experiences. Journal of Counseling \& Development, 80, 180-187.

Kmec, J. A. (2013). Why academic STEM mothers feel they have to work harder than others on the job. International Journal of Gender, Science, \& Technology, 5. Retrieved from http://hdl.handle.net/2376/6017

KMPG. (2015). Survey on gender balance in senior management positions. Analysis of survey results 2015. Retrieved https://www.um.edu.mt/_ data/assets/pdf_file/0010/278056/KPMGSurveyReportFINALRevised.pdf.

Lahiri-Dutt, K. and Pallabi, S. (2014). Women's 'Double Day' in Middle-class Homes in Small-town India, Contemporary South Asia, 1-17, DOI: 10.1080/ 09584935.2014.979762.

Lincoln, Y. S., \& Guba, E. G. (1985). Naturalistic Inquiry. Newbury Park, CA: Sage Publications.

Luckmann, T. (2008) On Social Interaction and the Communicative Construction of Personal Identity, Knowledge and Reality. Organisation Studies, 29, 277-290.

Mason, M. A. \& Goulden, M. (2004). Marriage and baby blues: Redefining gender equity. Annals of the American Academy of Political and Social Science, 596, 86-103.

Mason, M., A. Wolfinger, N. H. \& Goulden, M. (2013). Do babies matter: Gender in the ivory tower. New Brunswick, NJ: Rutgers University Press.

McKie, L. \& Jyrkinen, M. (2018). Early to mid-career women managers. Experiences of gendered age, care and work in Research Handbook of Diversity and Careers - New Horizons in Management.

McKinsey and Co. (2021). Women In The Workplace 2021. Accessible at: https://wiwreport.s3.amazonaws.com/Women_in_the_Workplace_2021.pdf

McNamee, S. \& Gergen, K.J. \& Associates (1999). Relational responsibility: Resources for sustainable dialogue. Thousand Oaks, CA: Sage.

Miles, M. B., \& Huberman A. M. (1994). (2nd Ed.). Qualitative Data Analysis: An expanded sourcebook. Sage Publications Inc.

Miles, M. B., Huberman, A. M., \& Saldana, J. (2014). (3rd Ed.). Qualitative Data Analysis: A Methods Sourcebook. Sage Publications Inc.

Mirick, R. G. and Wladkowski, S. P. (2018). "Pregnancy, Motherhood, and Academic Career Goals: Doctoral Students' Perspectives." Affilia 0(0): 0886109917753835.

Mostafa, M. (2003). "Attitudes towards women who work in Egypt”. Women in Management Review, 18: 5, 25266.

Moustakas, C. (1994). Phenomenological Research Methods. Sage, Thousand Oaks, CA.

Moustakas, C. (1994). Phenomenological research methods. Thousand Oaks, CA: Sage.

Nightingale, D. and Cromby, J. (2002) Social Constructionism as Ontology. Theory \& Psychology, 12, 701-713.

NSO, 2015. News Release: Labour Force Survey: Q1/2015. Retrieved from https://nso.gov.mt/en/News_Releases/View_by_Unit/Unit_C2/Labour_Market_Statistics/Documents/201 5/News2015_120.pdf on 30/05/18. 
NSO, 2018. International Day of Families: 2018. Retrieved from https://nso.gov.mt/en/News_Releases/View_by_Unit/Unit_C1/Living_Conditions_and_Culture_Statistics /Documents/2018/News2018_075.pdf on 25/05/18.

Ortner, S. (1974) "Is female to male as nature is to culture?" pp. 67-87 in Woman, Culture, and Society, edited by M. Z. Rosaldo and L. Lamphere. Stanford, CA: Stanford University Press.

Pace, S. (2017). More women land top jobs. Times of Malta. Retrieved from https://www.timesofmalta.com/articles/view/20170205/life-features/More-women-land-top-jobs.638693 on $4 / 08 / 18$.

Pas, B., et al. (2011). "Explaining career motivation among female doctors in the Netherlands: the effects of children, views on motherhood and work-home cultures." Work, Employment and Society, 25: 3, 487-505.

Ponterotto, J. (2005). Qualitative research in counselling psychology: A primer on research paradigms and philosophy of science. Journal of Counselling Psychology, 52: 2, 126-136.

Roulston, K. (2014). Analysing Interviews. In Uwe, F. The SAGE Handbook of Qualitative Data Analysis. Sage Publications Inc.

Schwartz, B. (1991) Social Change and Collective Memory: The Democratization of George Washington. American Sociological Review, 56, 221-236.

SCP (Sociaal en Cultureel Planbureau [The Netherlands Institute for Social Research]). (2008). Emancipation Monitor. The Hague: SCP.

Strauss, A. \& Corbin, J. (1990). Basics of Qualitative Research: Grounded Theory Procedures and Techniques, Sage, Newbury Park, CA.

Wayne, S - (2017) Scott Wayne "Hiring data show top-level women still a minority in hotels" published on the 23rd of August, 2017. (https://www.hotelmanagement.net/operate/hiring-datashows-top-level-womenstill-a-minority-hotels).

Wilton, S., \& Ross, L. (2017). Flexibility, sacrifice, and insecurity: A Canadian study assessing the challenges of balancing work and family in academia. Journal of Feminist Family Therapy, 29, 1-2, 66-87. doi:10.1080/09852833.2016.1272663.

Wingfield, B. (2011). "Juggling the demands of a career and motherhood: Perspectives of an academic in science." South African Journal of Science, 2011: 107(9/10).

Young, D. S. \& Wright, E. M. (2001). Mothers making tenure. Journal of Social Work Education, 37, 555-568. 